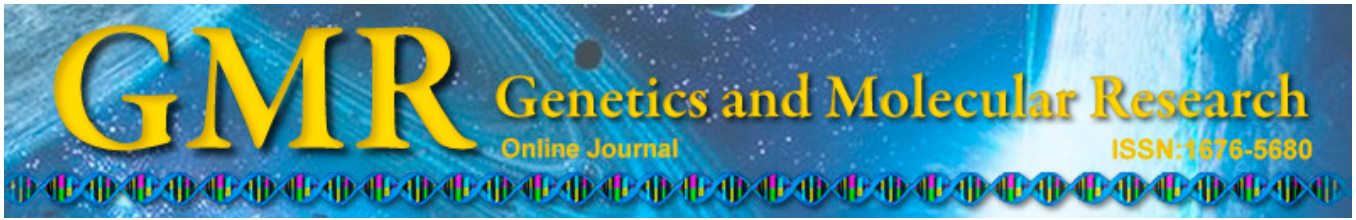

\title{
Expression of drought tolerance genes in tropical upland rice cultivars (Oryza sativa)
}

\author{
R.D.D. Silveira ${ }^{1,4}$, F.R.M. Abreu ${ }^{2,4}$, S. Mamidi $^{3}$, P.E. McClean ${ }^{3}$, R.P. Vianello ${ }^{4}$, \\ A.C. Lanna ${ }^{4}$, N.P. Carneiro ${ }^{5}$ and C. Brondani ${ }^{4}$ \\ ${ }^{1}$ Instituto de Ciências Biológicas, Universidade Federal de Goiás, \\ Goiânia, GO, Brasil \\ ${ }^{2}$ Escola de Agronomia, Universidade Federal de Goiás, Goiânia, GO, Brasil \\ ${ }^{3}$ Department of Plant Sciences, North Dakota State University, Fargo, ND, USA \\ ${ }^{4}$ Laboratório de Biotecnologia, Embrapa Arroz e Feijão, \\ Santo Antônio de Goiás, GO, Brasil \\ ${ }^{5}$ Núcleo de Biotecnologia Aplicada, Embrapa Milho e Sorgo, \\ Sete Lagoas, MG, Brasil \\ Corresponding author: C. Brondani \\ E-mail: claudio.brondani@embrapa.br
}

Genet. Mol. Res. 14 (3): 8181-8200 (2015)

Received August 7, 2014

Accepted February 5, 2015

Published July 27, 2015

DOI http://dx.doi.org/10.4238/2015.July.27.6

\begin{abstract}
Gene expression related to drought response in the leaf tissues of two Brazilian upland cultivars, the drought-tolerant Douradão and the drought-sensitive Primavera, was analyzed. RNAseq identified 27,618 transcripts in the Douradão cultivar, with 24,090 (87.2\%) homologous to the rice database, and 27,221 transcripts in the Primavera cultivar, with $23,663(86.9 \%)$ homologous to the rice database. Gene-expression analysis between control and water-deficient treatments revealed 493 and 1154 differentially expressed genes in Douradão and Primavera cultivars, respectively. Genes exclusively expressed under drought were identified for Douradão, including two genes of particular interest coding for the protein peroxidase precursor, which is involved in three distinct metabolic pathways. Comparisons between the two drought-exposed cultivars revealed 2314 genes were
\end{abstract}


differentially expressed (978 upregulated, 1336 downregulated in Douradão). Six genes distributed across 4 different transcription factor families (bHLH, MYB, NAC, and WRKY) were identified, all of which were upregulated in Douradão compared to Primavera during drought. Most of the genes identified in Douradão activate metabolic pathways responsible for production of secondary metabolites and genes coding for enzymatically active signaling receptors. Quantitative PCR validation showed that most gene expression was in agreement with computational prediction of these transcripts. The transcripts identified here will define molecular markers for identification of Cisacting elements to search for allelic variants of these genes through analysis of polymorphic SNPs in GenBank accessions of upland rice, aiming to develop cultivars with the best combination of these alleles, resulting in materials with high yield potential in the event of drought during the reproductive phase.

Key words: Differential gene expression; Functional annotation; Water deficit; Brazilian rice cultivars.

\section{INTRODUCTION}

The future of global agriculture will encounter great challenges in relation to global warming, water shortages, demographic growth, and degradation of the environment, in addition to a projected increase in agricultural demand of $70 \%$ by 2050 to keep up with the growth of the world's population (Godfray et al., 2010). Rice (Oryza sativa L.) is part of this scenario because it is the most highly consumed cereal grain around the world. Technical advancements brought by genomics may result in an increase in rice productivity, even under suboptimal crop conditions, such as the occurrence of drought periods. The area cultivated with rice is estimated to be approximately 164 million hectares, with production of 722 million tons per year, and $75 \%$ of this area occurs within floodplain systems. With a reduction in crop water availability due to the cost of electrical energy or due to competition for human consumption, dry-land cultivation systems may constitute a viable alternative. In Brazil, although upland rice fields represent $55 \%$ of the total cultivated area, their production barely represents $25 \%$ of total Brazilian production (Santos and Rabello, 2008).

Rice is sensitive to drought conditions mainly during its reproductive phase, when even moderate stress can drastically reduce yield. As a result of drought stress, a number of genes are expressed in these plants, triggering a complex network of responses, including the perception and recognition of stress signals, the activation of adaptive programs, and even the activation of genes involved in the downstream response (Boudsocq and Laurière, 2005). The products of stress-induced genes can be classified into two groups, one comprising genes that directly protect the plant against the environmental stressor, such as the biosynthesis of various osmoprotectants, proteins abundant during late embryogenesis, chaperones, and detoxification enzymes; and a second group comprised of genes regulating gene expression and signal transduction in response to stress, including transcription factors, protein kinases, and proteins involved in phosphoinositide metabolism (Ding et al., 2013). Among the noteworthy mechanisms for physiological responses are the relative reduction in water content, pigment degra- 
dation, decrease in stomatal conductance, reduction of internal $\mathrm{CO}_{2}$ concentration, activation of respiration, and reduction in net photosynthesis rate and cellular growth (Cattivelli et al., 2008).

Since tolerance to drought stress is multigenic and quantitative in nature (Collins et al., 2008), understanding the key molecular mechanisms for advanced selective breeding purposes is a massive challenge. Plant responses to drought consist of morphological, physiological, and biochemical changes that decrease plant exposure to stress and/or limit damage and facilitate recovery of impaired systems. Understanding abiotic stress responses in plants is difficult due to the complexity, interrelationships, and variability of mechanisms and molecules involved. However, it is important to understand the mechanisms by which tolerant cultivars respond to stress in order to select genes that may be useful in rice breeding programs (Recchia et al., 2013).

Gene-expression analysis in rice exposed to drought-stress conditions has been extensively studied using diverse technologies, such as DNA microarrays and RNA-seq, based on the massive sequencing of cDNA using next-generation sequencing technology (Nagalakshmi et al., 2008). Studies emphasizing the transcriptome of $O$. sativa increase the possibilities of discovery and exploration of novel genes and expand opportunities for detailing previously described genes that may be the target of more specific functional analyses, thus, effectively contributing to increasing plant tolerance to drought-induced stress. While hundreds of genes involved in the drought-stress response have been identified in rice, many of which are well characterized, the function of many genes remains unknown. A considerable portion of these studies is focused on the identification of genes upregulated during drought, comparing the gene-expression profiles of drought-tolerant and drought-sensitive cultivars under normal irrigation conditions $v s$ water-deficient conditions (Wang et al., 2011).

Rabbani et al. (2003) identified 75 differentially expressed genes in the subspecies japonica in drought conditions using microarray technology. Similarly, Moumeni et al. (2011) compared genes that were differentially expressed under water-deficient conditions in roots of isogenic lines of the subspecies indica with different drought-tolerance profiles and identified genes involved in the production of secondary metabolites, amino acid metabolism, stimuli response, defense response, transcription, and signal transduction. Studies performed with RNA-seq technology have the advantage of detecting even genes with low levels of expression and those not detected by commercial gene expression microarrays (Civelek and Lusis, 2014). When considering rice, these studies address questions such as embryo development and responses to biotic stimuli (Gao et al., 2013). The objective of the present study was to identify transcripts involved in drought tolerance in two upland rice varieties by means of transcriptome analysis using RNA-seq.

\section{MATERIAL AND METHODS}

\section{Plant materials and experimental treatment}

A drought-tolerant Douradão upland rice cultivar and a drought-sensitive Primavera cultivar were used to screen their performance under drought treatments. These cultivars are from the subspecies japonica and were chosen based on their different physiological characteristics and due to their use as parental lines in breeding programs of the Embrapa National Center for Research on Rice and Beans (Centro Nacional de Pesquisa de Arroz and Feijão, CNPAF). The Douradão cultivar was developed in 1989 through a partnership between the 
Agricultural Research Company of Minas Gerais (Empresa de Pesquisa Agropecuária de Minas Gerais, EPAMIG) and the Embrapa National Center for Research on Rice. This cultivar was produced from the crossing IAC 25/63-83 and presents a short cycle of 95 days on average. The Primavera cultivar is considered semi-precocious due to its cycle of 115 days. This latter cultivar was developed in 1987 by EPAMIG by crossing the parental lines IRAT 10 and LS 85-158.

The drought-tolerance experiment was conducted in a greenhouse at Embrapa CNPAF (Santo Antônio de Goiás, Brazil), in the 2010/2011 growing season. For the experiment, approximately 10 seeds of the cultivars were sown in pots, and after germination, five randomly chosen plants were maintained in each pot. Water restriction was applied in two periods: in period 1 the interruption in irrigation occurred between vegetative stage V3 (according to the classification of Counce et al., 2000), [17 days after sowing (DAS) for Douradão and 15 DAS for Primavera] and V6 (35 DAS for Douradão and 34 DAS for Primavera); and in period 2, the interruption in irrigation began in reproductive stage R3 (panicle emergence-55 DAS for Douradão and 64 DAS for Primavera) through R6 (milky grain-66 DAS for Douradão and 75 DAS for Primavera). During these two periods, four irrigation regimes were used: Group A (control group)-a set of plants with the availability of water set at field capacity (FC); Group B-a set of plants exposed to $70 \%$ of FC; Group C-a set of plants exposed to $50 \%$ of $\mathrm{FC}$; and Group D-a set of plants exposed to $30 \%$ of FC. Once $50 \%$ of the plants from each cultivar reached vegetative stage V3 (the beginning of the first cycle of water deficiency), irrigation was interrupted so that the different water regimes could be reached in the soil until vegetative stage V6. Irrigation continued normally for the set of plants exposed to the second period of water deficiency until more than $50 \%$ of plants in this set of pots reached reproductive stage $\mathrm{R} 3$, at which time water restriction was enforced and lasted until stage R6.

The experimental design was a split-plot randomized block. Six replicates were used for each cultivar and for each cycle of water deficiency. Of the six replicates, three pots were used for sampling of the plant material, and three pots were maintained until the end of the rice cycle to determine productivity. Replicates were established according to the water regime, genotype, and water-deficiency cycle, for a total of two plots (Period 1 and 2) with 48 pots each. To establish the amount of water per pot for each water regime, the FC of the soil was determined, defined as the maximum water content retained by the soil after the excess has been drained, recording the maximum mass of the pot (soil + water) as well as the water volume corresponding to $100 \%$ of FC. The mass was obtained using an electronic scale (Marte, LC20 model), and the amount of water added was measured using a graduated cylinder. The duration of stress varied with the severity of the treatment: for the plants exposed to $70 \%$ of FC, the duration of the stress was 10 days; for the plants exposed to $50 \%$ of $\mathrm{FC}$, the duration was 6 days; and for the plants exposed to $30 \%$ of FC, the duration was one day.

At the end of the water-restriction period, the stressed plants were irrigated again until the end of the cultivation cycle to determine their productivity (g grains/pot) to evaluate the severity of water deprivation. To analyze the transcriptome, the developmental stage of the rice plant most sensitive to water restriction was chosen, that is, the stage in which the plants' productivity reduced most drastically. Next, with the objective of defining the appropriate water treatment that could induce the molecular responses to water deficit, we used the irrigation treatment that would induce a reduction in plant productivity greater than $50 \%$ as a parameter. Average values across treatments were compared according to the Tukey test, using the ExpDes statistical package in v2.13.2 of the R software (R Development Core Team, 2008). 


\section{RNA isolation}

To analyze the transcriptome, samples of leaf tissue from control and droughtstressed plants were collected on the last day of water restriction of each water-deprivation cycle, immediately placed in liquid nitrogen, and stored at $-80^{\circ} \mathrm{C}$. Apical leaves (the last fully extended leaf from the top to the base of the main stem) were used as the plant material for total RNA extraction. This extraction was performed using a PureLink ${ }^{\mathbb{B}}$ RNA Mini Kit (Ambion ${ }^{\circledR}$, USA) following the manufacturer protocol. Total RNA was resuspended in RNAse-free water and stored at $-80^{\circ} \mathrm{C}$. RNA quantity and quality were evaluated using a NanoVue $^{\mathrm{TM}}$ (GE Healthcare UK Ltd., England) and a BioAnalyzer 2100 (Agilent Technologies, CA, USA), respectively.

\section{RNA-seq and bioinformatic analysis}

RNA samples were sent to the Beijing Genomics Institute (BGI). A total of four cDNA libraries were developed; two cDNA libraries for each sample, one for the water-deficiency treatment, and the fourth one for the control treatment, followed by sequencing using an Illumina HiSeqTM 2000 platform. The collected data were filtered by BGI and submitted for alignment and mapping against a rice reference genome (O. sativa ssp japonica, NipponbareMSU Rice Genome version 7.0) using the software TopHat v2.04 (Trapnell et al., 2013). The software package Cufflinks v2.0.01 (Trapnell et al., 2013) was used to build the assemblies for each library and to identify differentially expressed genes (DEG). The reads for each of the samples for the four cDNA libraries were normalized, taking into account the size of the genes, the size of the library (sample), and the number of reads of each gene, considering the abundance of reads per kilobase of regions expressed for every million mapped reads (reads per kilobase of exon model per million mapped reads). Two tests were used to consider the differences in gene expression among the genes, for which the same transcript was required to be present in both of the samples to be compared, which were q values $\leq 0.001$ and $\mid \log 2$ ratio| $>2$. Common and exclusive DEG with respect to treatments and genotypes were considered.

The reads were annotated using the BLASTX algorithm (Altschul et al., 1997) and cross-referenced with the non-redundant rice protein database using default settings in the tool blast+ from the NCBI C++ Toolkit package. With the goal of attributing a putative function to the global set of transcripts using gene ontology (GO) terms, we used the BLAST2GO tool on the BLASTX hits (Conesa et al., 2005). The parameters adopted for the annotation were the default settings for BLAST2GO (an E value $<1.0 \mathrm{E}-6$ and annotation cut-off $=20$ ), which were used to functionally categorize the transcript of GO categories. Differentially expressed genes were analyzed using the agriGO tool, which has a web interface (http://bioinfo.cau.edu.cn/ agriGO) and is integrated in the GO database with an emphasis on plant species. A GO enrichment analysis was performed with the singular enrichment analysis tool (SEA, http://bioinfo. cau.edu.cn/agriGO/analysis.php) with a false discovery rate (FDR) and $\mathrm{P} \leq 0.05$. Additionally, differentially expressed genes were placed in metabolic pathways using the Kyoto Encyclopedia of Genes and Genomes (KEGG), available at http://www.genome.jp/kegg/.

From the differentially expressed genes between Douradão and Primavera, a search for potential transcription factors was performed. To identify the transcription factors, hits derived from the alignment (BLASTX) were cross-referenced with the plant transcription-factor database plant (PlnTFDB) available at http://plntfdb.bio.uni-potsdam.de/v3.0/. 


\section{Reverse transcription quantitative PCR validation of RNA-seq}

Ten genes were selected for validation using reverse transcription quantitative PCR (RT-qPCR) (Supplementary table 1). Primers set for each gene were designed in the span exon-exon junctions using the OligoPerfect ${ }^{\mathrm{TM}}$ Designer (http://tools.lifetechnologies.com/ content.cfm?pageid=9716). Total RNA was treated with DNAse I (Invitrogen $\left.{ }^{\mathrm{TM}}, \mathrm{CA}, \mathrm{USA}\right)$ to avoid DNA contamination. RNA $(1 \mu \mathrm{g})$ was reverse transcribed using Superscript II reverse transcriptase (Invitrogen ${ }^{\mathrm{TM}}$ ) with random primers following the manufacturer protocol. RTqPCR experiments were conducted using Platinum ${ }^{\circledR}$ SYBR $^{\circledR}$ Green qPCR SuperMix-UDG with ROX (Invitrogen ${ }^{\mathrm{TM}}$ ) and were carried out on a 7500 Real-Time PCR System (Applied Biosystems ${ }^{\circledR}$, USA). The reactions conditions were as follows: $50^{\circ} \mathrm{C}$ for $2 \mathrm{~min}, 95^{\circ} \mathrm{C}$ for 2 min, followed by 40 cycles of $95^{\circ} \mathrm{C}$ for $15 \mathrm{~s}$ and $60^{\circ} \mathrm{C}$ for $30 \mathrm{~s}$. The total volume of $20 \mu \mathrm{L}$ in each tube contained $1 \mu \mathrm{L} \mathrm{cDNA}(50 \mathrm{ng} / \mu \mathrm{L})$, and the volume of water and reverse and forward primers were variable for each gene, according to adjustments made for optimal concentration of each primer (Tables S2 and S3 ). All RT-qPCR reactions were performed in triplicate, and the results were analyzed with the DataAssist ${ }^{\mathrm{TM}}$ Software (Life Technologies, USA) based on the delta-delta-Ct method (Livak and Schmittgen, 2001). A heat dissociation curve $\left(60^{\circ}\right.$ to $95^{\circ} \mathrm{C}$ ) following the final cycle of the PCR was checked to assess the specificity of the PCR amplification. The detection threshold cycle for each reaction was normalized against the expression levels of the rice reference genes Actin (ACTX3), Glyceraldehyde-3-phosphate dehydrogenase (GAPDH), and Eukaryote Elongation factor (EEF $\alpha$ ) (Table S1).

\section{RESULTS}

\section{RNA-seq experiments}

The largest reduction in productivity was observed when water restriction was applied during the reproductive phase (the second period of water restriction) rather than during the vegetative phase (the first period of water restriction), which was expected given the greater opportunity for the rice plant to recover from the water deficit during its initial phase of development (Table 1). After the definition of the drought period, we selected the water treatments that induced a reduction in productivity greater than $50 \%$ in relation to the controls. For the Douradão cultivar, the greatest difference in productivity ( $83.99 \%$ reduction) was observed in the treatment with $30 \%$ of FC; while for Primavera, the treatment with the greatest difference was that of $50 \%$ of FC. These results confirm the higher tolerance of the Douradão cultivar compared to the Primavera cultivar.

RNA-seq from all the libraries generated 201,509,058 paired-end reads of $100 \mathrm{bp}$. The total coverage of reads in the rice genome was approximately 46 times, and the coverage in relation to DNA coding sequences (CDS) was approximately 200 times. The average coverage of the rice genome and the average coverage of CDSs were 11.65 times and 49.81 times, respectively (Table 2). The reads mapped and aligned with the program TopHat totaled $85.02 \%$ of the total number of sequenced reads, and by using an alignment of sequences from each library it was possible to make comparisons between samples to identify differentially expressed genes. For the Douradão cultivar, of the 27,618 sequenced transcripts, 24,090 (87.2\%) were similar to the Nipponbare reference genome (MSU Rice Genome version 7.0), while for Primavera, 23,663 transcripts (86.9\%) were similar to Nipponbare. 
Table 1. Average yield (g grain/pot) of the upland rice cultivars Douradão and Primavera, grown under optimal watering $(100 \% \mathrm{FC})$ and under drought stress $(70,50$, and $30 \% \mathrm{FC})$.

\begin{tabular}{|c|c|c|c|c|c|c|c|c|}
\hline \multirow[t]{2}{*}{ Treatment } & \multicolumn{4}{|c|}{ Vegetative stage } & \multicolumn{4}{|c|}{ Reproductive stage } \\
\hline & $\begin{array}{l}\text { Douradão } \\
\text { g grain/pot }\end{array}$ & $\begin{array}{l}\text { Reduction } \\
(\%)\end{array}$ & $\begin{array}{l}\text { Primavera } \\
\text { g grain/pot }\end{array}$ & $\begin{array}{l}\text { Reduction } \\
(\%)\end{array}$ & $\begin{array}{l}\text { Douradão } \\
\text { g grain/pot }\end{array}$ & $\begin{array}{l}\text { Reduction } \\
(\%)\end{array}$ & $\begin{array}{l}\text { Primavera } \\
\text { g grain/pot }\end{array}$ & $\begin{array}{c}\text { Reduction } \\
(\%)\end{array}$ \\
\hline $100 \%$ of $\mathrm{FC}$ & $26.16^{\mathrm{a}}$ & - & $16.64^{\mathrm{a}}$ & - & $28.54^{\mathrm{a}}$ & - & $18.59^{\mathrm{a}}$ & - \\
\hline $70 \%$ of FC & $23.14^{\text {ab }}$ & 11.55 & $11.88^{\mathrm{a}}$ & 28.60 & $25.46^{\mathrm{a}}$ & 10.80 & $16.15^{\mathrm{ab}}$ & 13.12 \\
\hline $50 \%$ of $\mathrm{FC}$ & $20.90^{\mathrm{ab}}$ & 20.10 & $11.70^{\mathrm{a}}$ & 29.68 & $18.64^{\mathrm{a}}$ & 34.69 & $8.20^{\mathrm{b}}$ & 55.9 \\
\hline $30 \%$ of FC & $14.56^{\mathrm{b}}$ & 55.65 & $3.46^{\mathrm{b}}$ & 79.2 & $4.57^{\mathrm{b}}$ & 83.99 & $0^{\mathrm{c}}$ & 100 \\
\hline
\end{tabular}

Letters ${ }^{\mathrm{a}}$ and ${ }^{\mathrm{b}}$ indicate significant differences (Tukey's test) between the average yield in relation to water treatments for each genotype at each stage of development. Mean comparison refers to the treatment of each genotype, i.e., the mean values were compared within each data column. Yield reduction, in percentage, is related to the decrease in yield of drought stressed plants compared to the yield of control plants.

Table 2. Description of the sequenced libraries (RNA-seq) from leaf tissues in the Douradão and Primavera cultivars.

\begin{tabular}{lrccc}
\hline Libraries & No. of reads & No. of mapped reads & CDS coverage (91 MB) & Genome coverage (389 MB) \\
\hline Douradão $100 \%$ & $51,193,382$ & $46,173,215$ & 50.74 & 11.87 \\
Douradão 30\% & $51,619,472$ & $45,822,301$ & 50.35 & 11.78 \\
Primavera 100\% & $49,164,344$ & $44,100,840$ & 48.47 & 11.33 \\
Primavera 50\% & $49,531,860$ & $45,214,807$ & 49.68 & 11.62 \\
Total & $201,509,058$ & $181,311,163$ & 199.24 & 46.6 \\
Average & $50,377,265$ & $45,327,790$ & 49.81 & 11.65 \\
\hline
\end{tabular}

\section{Global GO annotation}

A functional classification of the sequences from all four libraries according to $\mathrm{GO}$ identified 26,159 genes across all the libraries (Figure 1), of which 17,270 (66\%) were annotated and distributed in three main functional categories: biological process, with 15 subcategories; cellular component, with 12 subcategories; and molecular function, with 8 subcategories (Figure 1). For the biological process category, the three subcategories with the greatest number of genes were metabolic process (10,316 genes), cellular process (9932 genes), and response to stimulus (3598 genes). For the cellular component category, the three subcategories with the greatest number of genes were cells (11,904 genes), cell parts (10,765 genes), and organelles (6881 genes). For the molecular function category, the three subcategories with the greatest number of genes were binding (8077 genes), catalytic activity (7256 genes), and transcription regulatory activity (1203 genes). From the 26,159 genes, 6720 were placed in 126 metabolic pathways that coded for 546 different types of enzymes (Table 3).

\section{Differential gene expression and functional annotation}

In the leaf tissues of the tolerant cultivar Douradão, 493 differentially expressed genes were identified between the control treatment and the $30 \%$ of FC treatment. Of these, 374 genes were upregulated and 119 genes were downregulated during the water-deficiency treatment (Figure 2). For the susceptible cultivar Primavera, more than twice as many DEG (1154) were identified between the control and $50 \%$ of FC treatment. Of these, 752 genes were upregulated and 402 were downregulated during water deficiency (Figure 2). 


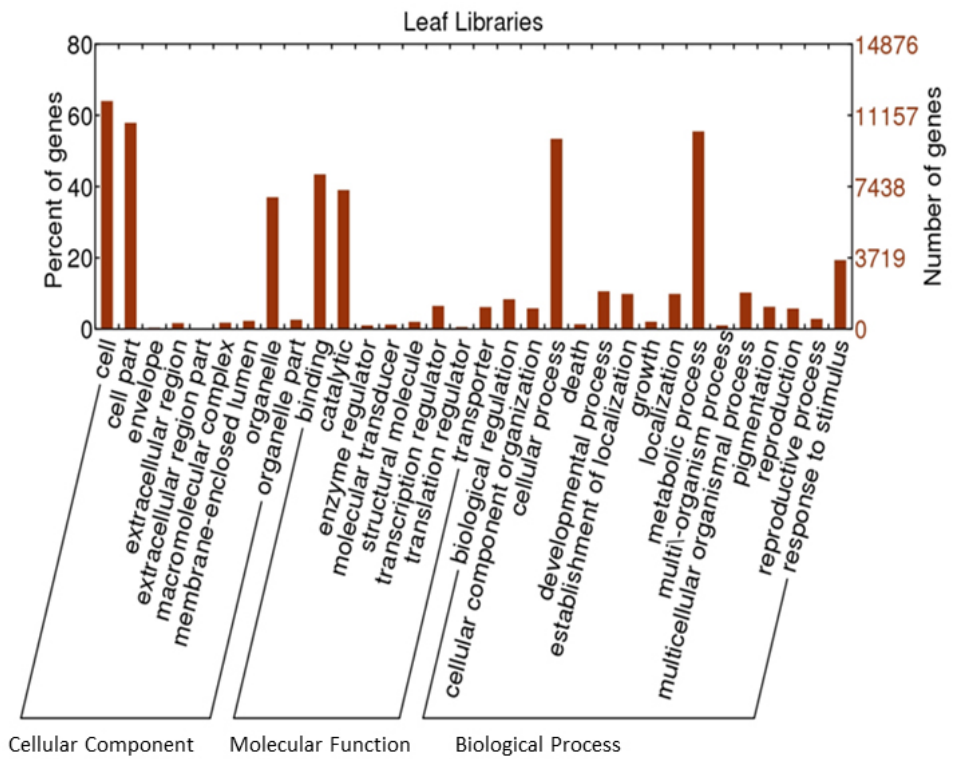

Figure 1. Annotation based on Gene Ontology terms using Blast2GO of all sequences derived from leaf tissue libraries of Douradão and Primavera cultivars.

Table 3. Metabolic pathways with the largest number of sequences annotated by KEGG.

\begin{tabular}{|c|c|c|}
\hline Pathway & No. of annotated sequences & Pathway ID \\
\hline Purine metabolism & 457 & ko00230 \\
\hline Starch and sucrose metabolism & 313 & ko00500 \\
\hline Methane metabolism & 209 & ko00680 \\
\hline Amino sugar and nucleotide sugar metabolism & 182 & ko00520 \\
\hline Thiamine metabolism & 168 & ko00730 \\
\hline Pyrimidine metabolism & 166 & ko00240 \\
\hline Phenylalanine metabolism & 152 & ko00360 \\
\hline Galactose metabolism & 139 & ko00052 \\
\hline Glycolysis / Gluconeogenesis & 139 & ko00010 \\
\hline Phenylpropanoid biosynthesis & 126 & ko00940 \\
\hline Glycerolipid metabolism & 119 & ko00561 \\
\hline Glutathione metabolism & 118 & ko00799 \\
\hline Carbon fixation in photosynthetic organisms & 114 & ko00710 \\
\hline Cysteine and methionine metabolism & 110 & ko00270 \\
\hline Pentose phosphate pathway & 102 & ko00030 \\
\hline Glycerophospholipid metabolism & 99 & ko00564 \\
\hline alpha-Linolenic acid metabolism & 91 & ko00592 \\
\hline Pyruvate metabolism & 88 & ko00620 \\
\hline Nitrogen metabolism & 86 & ko00910 \\
\hline Oxidative phosphorylation & 86 & ko00190 \\
\hline
\end{tabular}

From the 493 differentially expressed genes in Douradão, 454 (92.08\%) were similar to proteins and 311 genes $(63.1 \%)$ were distributed across 28 different functional categories, of which the three main sets were enriched (FDR $\leq 0.05$ and $\mathrm{p} \leq 0.05$ ): biological process, molecular function, and cellular component (Figure 3). In the biological process category, five subcategories were enriched: response to stimulus (GO:0050896; 93 genes, 29.9\%); signaling (GO:0023052; 2 genes, 13.5\%); cellular process (GO:0050794; 35 genes, 11.25\%); signaling process (GO:0023046); and biological regulation (GO:0065007; 41 genes, 13.18\%). Addition- 
ally, 168 genes enriched in the molecular function category had catalytic activity (GO:0003824).

From the 1154 genes differentially expressed in Primavera, 973 (84\%) were similar to proteins and $677(69.6 \%)$ were annotated in 27 subcategories within the three principal functional categories (Figure 4). In the subcategory response to stimulus (GO:0050896), three subcategories were identified: response to stress (GO:0006950; 134 genes, 19.8\%); response to abiotic stimulus (GO:0009628; 93 genes, 13.74\%); and response to endogenous stimulus (GO:0009719;68 genes, 10\%).

From the 374 genes upregulated by drought in the Douradão cultivar, 255 (68\%) were annotated according to GO terms (Figure 5). In the biological process category, 17 subcategories were identified, including metabolic process (178 genes), cellular process (142 genes), and response to stimulus (103 genes). From the total genes with functions attributed to response to stimulus, 65 genes were related to the subcategory response to stress, with only six genes upregulated in the drought treatment (all with $\mid \log 2$ ratio $\mid=1.80 \mathrm{E}+30$ ). These genes encode the peroxidase precursor (LOC_Os04g55740.1 and LOC_Os12g02060.1), the CHIT4Chitinase family protein precursor (LOC_Os03g30470.1), the disease resistance-responsive (dirigent-like protein) family protein (LOC_Os07g44250.1), the CHIT7-Chitinase family protein precursor (LOC_Os06g51050.1), and the NB-ARC domain-containing protein (LOC Os05g15040.4). Of these proteins, the protein peroxidase precursor (EC: 1.11.1.7) is the only one annotated in the KEGG database and described as actively participating in three different metabolic pathways: methane metabolism, phenylalanine metabolism, and phenylpropanoid biosynthesis. Thirty-five of $42(83.3 \%)$ signaling genes were detected as upregulated after the drought treatment, and from these, five were identified only in the drought treatment. Two of these genes, in addition to being placed in the category biological potential, were also classified in the subcategory response to stress: CHIT7 (LOC_Os06g51050.1) and CHIT4 (LOC_Os03g30470.1). Three other upregulated genes, ABC transporter ATP-binding protein (LOC_Os01g74470.1), the receptor-like protein kinase precursor (LOC_Os02g01800.1), and the receptor-like protein kinase HAIKU2 precursor (LOC_Os11g12560.1), have not been annotated to a rice metabolic pathway by KEGG.

In Primavera, 428 of 752 upregulated genes were previously annotated in rice (Figure 5). A total of 17 biological process subcategories were identified, of which the three with the highest number of genes were metabolic process ( 240 genes), cellular process (202 genes), and response to stimulus (116 genes). In the response to stimulus subcategory, 93 genes were involved in response to stress, and from these, nine genes were upregulated only in the drought treatment. These genes were: uncharacterized glycosyltransferase (LOC_Os01g07530.1); the early light-induced protein, the chloroplast precursor (LOC_Os01g14410.1); the HSP20/alpha crystallin family protein (LOC_Os03g15960.1); the CBS domain-containing membrane protein (LOC_Os03g63940.1); protein kinase (LOC_Os05g44030.1); dehydrogenase E1, a component domain-containing protein (LOC_Os06g13720.1); HVA22 (LOC_Os08g36440.1); annexin (LOC_Os09g20330.1); and the tyrosine protein kinase domain-containing protein (LOC_Os09g27010.1). Only two of these proteins were annotated by KEGG as belonging to a metabolic pathway: LOC_Os01g07530.1 (stachyose biosynthesis) and LOC_Os06g13720.1 (pyruvate metabolism, citrate cycle/TCA cycle, glycolysis/gluconeogenesis, and butanoate metabolism). In the cellular process category, abscisic aldehyde oxidase (LOC_Os03g57690.1) was upregulated and is associated with abscisic acid (ABA) biosynthesis.

From 2519 genes differentially expressed between control treatments of Douradão and Primavera, 983 were common to the 3297 genes differentially expressed considering the 
drought treatments (Figure 6). Subtracting the common genes, 2314 differentially expressed genes were identified (978 upregulated and 1336 downregulated in Douradão). From these, 1171 were annotated with GO terms and distributed across 26 functional subcategories, and the three main groups were biological process, molecular function, and cellular component (Figure 6). Within these groups, the categories with the highest number of genes were: 1) catalytic activity (GO:0003824) with 551 genes, of which 155 have functional kinase activity (GO:0016301), and 2) response to stimulus (GO:0050896) with 288 genes, 221 of which are related to the response to stress category (GO:0006950).

Among the 978 genes upregulated in Douradão, 324 were only expressed in the drought treatment, with the predominance of genes grouped in the most enriched subcategories: response to stress ( 46 genes) and kinase activity ( 34 genes). From the 46 genes related to response to stress, five were identified in metabolic pathways in the KEGG database, of which three expressed the previously identified protein peroxidase precursor (LOC_Os07g48050.1, LOC_Os01g73200.1, and LOC_Os12g02060.1), and two were annotated as response to stress, pleiotropic drug-resistance protein (LOC_Os01g42380.1), identified in the purine metabolism pathway, the T-complex protein (LOC_Os03g04970.1), and involved in the glyoxylate and dicarboxylate metabolism pathway. None of the 34 genes identified in the tolerant genotype under the subcategory kinase activity were annotated by the KEGG database; however, important genes involved in cellular signaling during the stress response in the Douradão cultivar were identified (Table 4). The 10 DEG from Douradão with increased expression when compared the drought treatment and the control treatment, as well as 10 DEG with highest expression when compared the drought treatment of Douradão and the drought treatment of Primavera, are shown in Table 5.

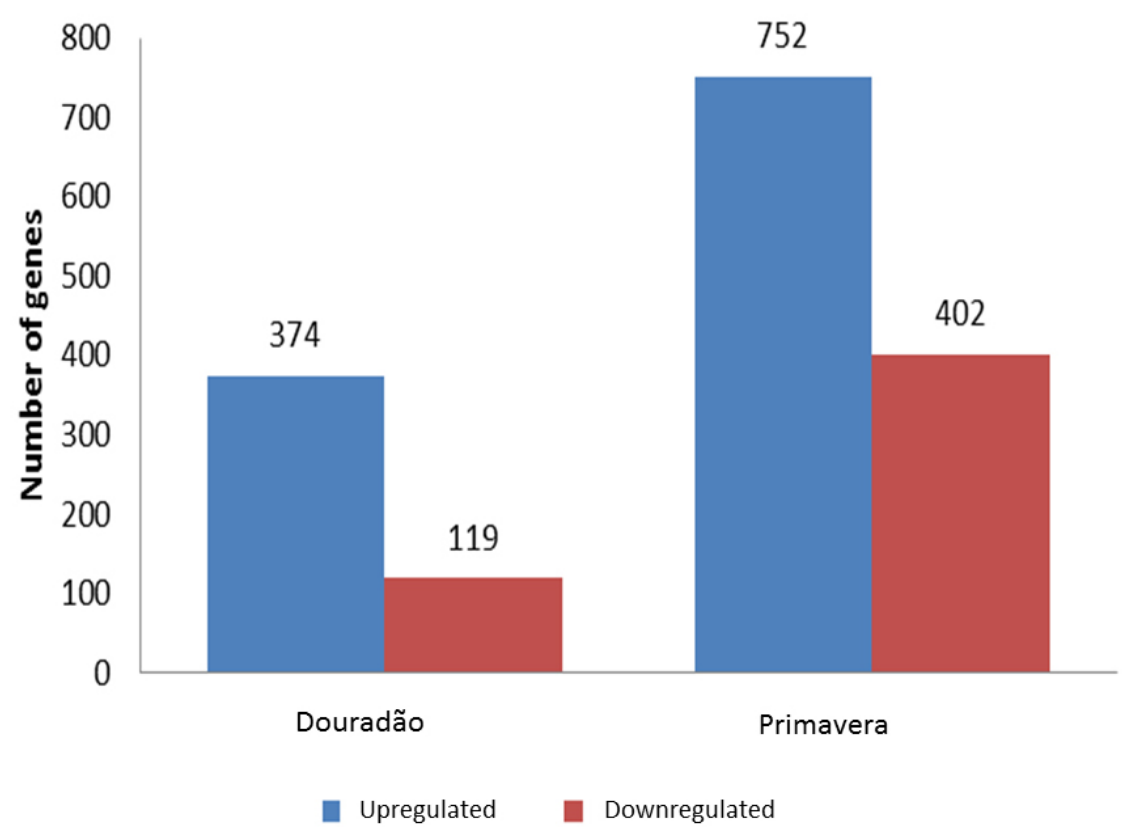

Figure 2. Differentially expressed genes between control (100\% FC) and drought treatments in Douradão and Primavera cultivars. 


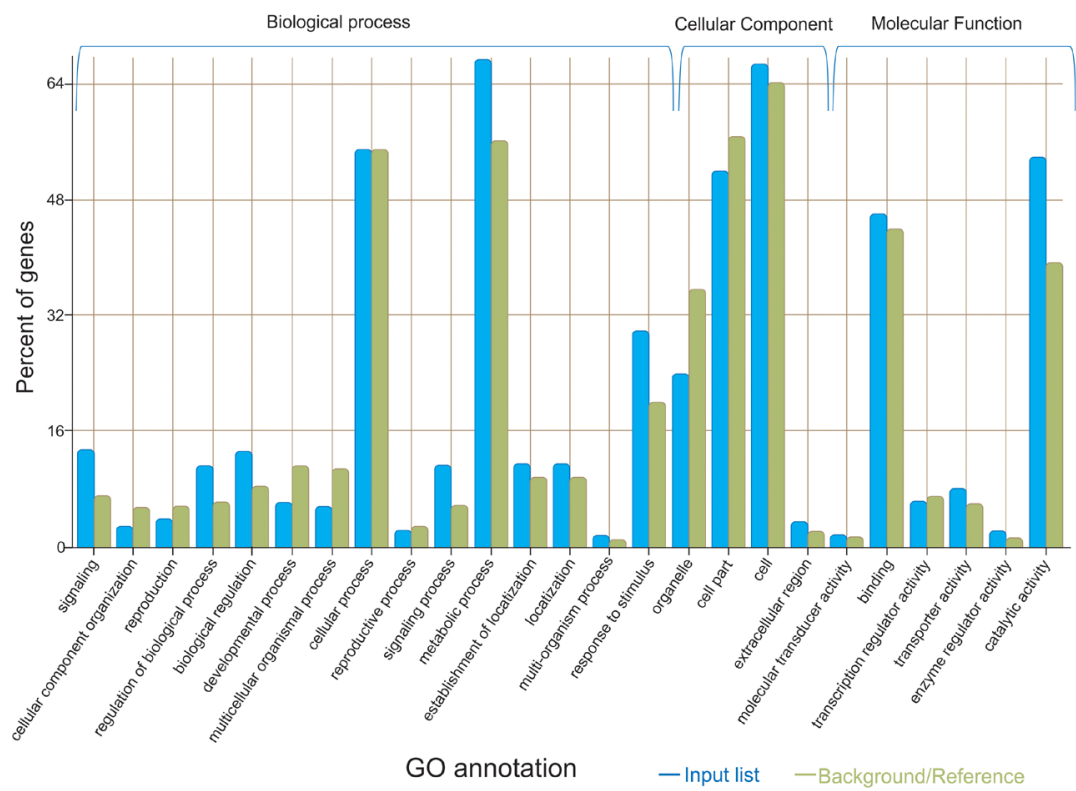

Figure 3. Classification of differentially expressed genes in the Douradão cultivar by Gene Ontology terms into 23 subcategories considering the three major functional categories: Biological Process, Cellular Component, and Molecular Function.

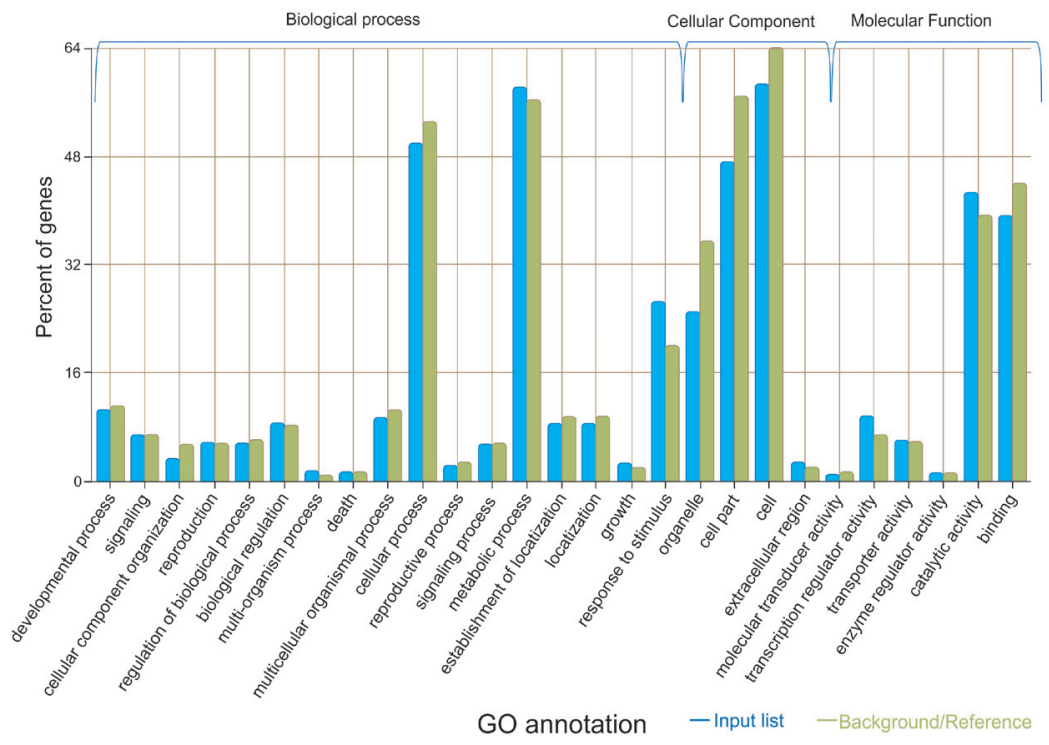

Figure 4. Classification of differentially expressed genes in the Primavera cultivar by Gene Ontology terms into 27 subcategories considering the three major functional categories: Biological Process, Cellular Component, and Molecular Function. 

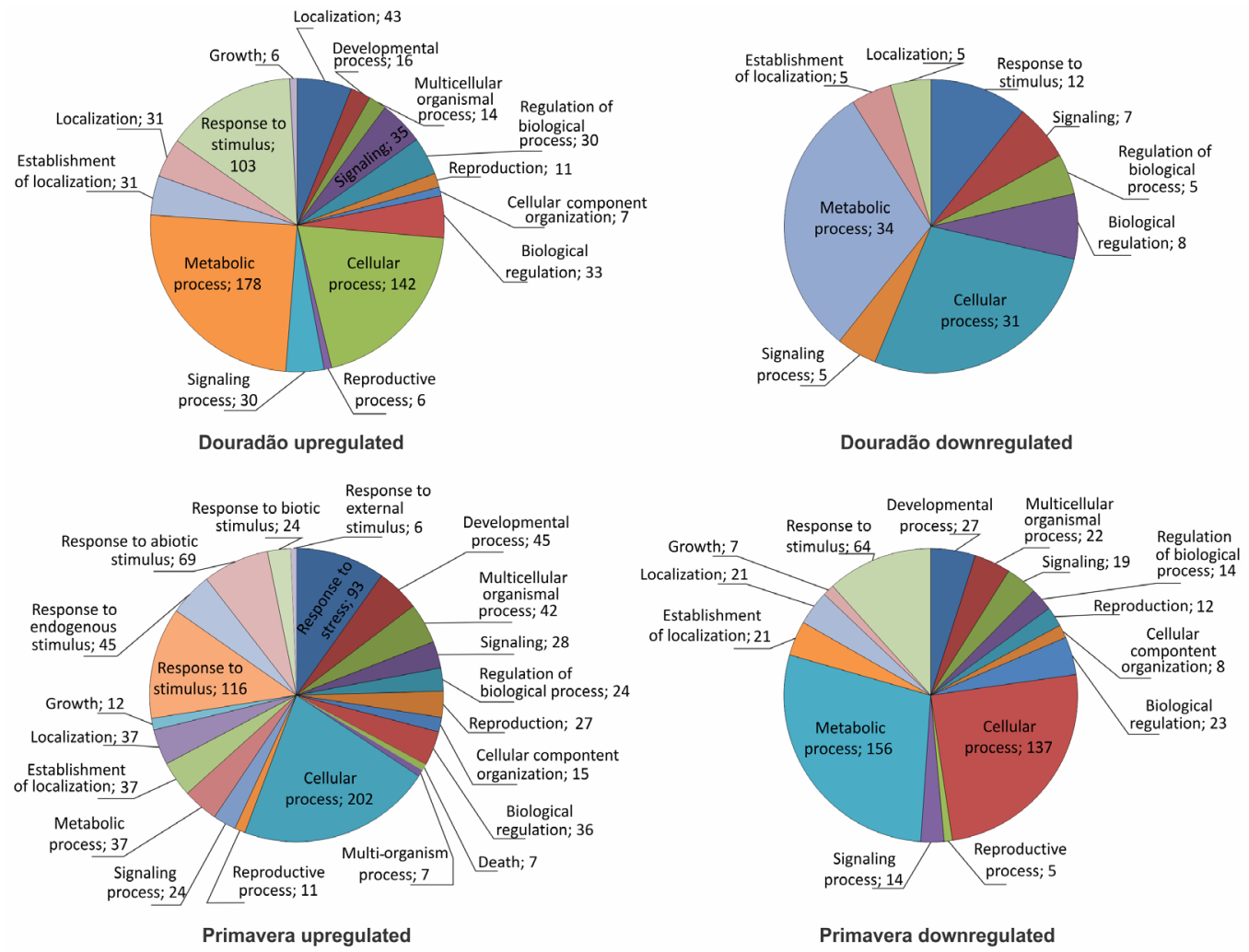

Figure 5. Functional classification of up and downregulated genes in the Douradão and Primavera cultivars under drought stress.

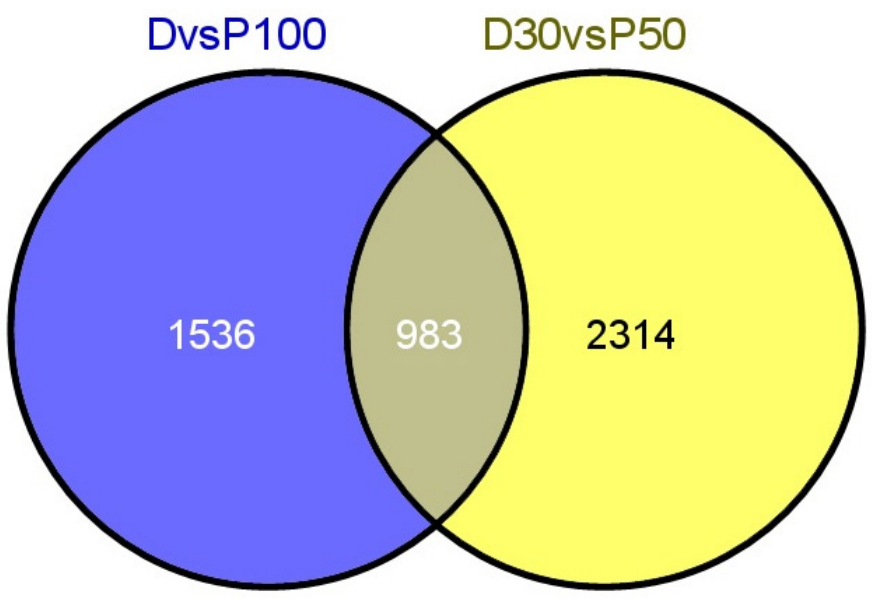

Figure 6. Venn diagram representing the number of differentially expressed genes between the Douradão and Primavera cultivars. DvsP 100-differentially expressed genes in the controls, D30vsP50-differentially expressed genes under drought treatment. 
Table 4. Unique genes in the Douradão cultivar under drought stress annotated in the kinase activity term by Gene Ontology. FPKM: fragments per kilobase per million mapped reads.

\begin{tabular}{|c|c|c|c|}
\hline Gene Model & Protein name & FPKM & Log2 (Fold-change) \\
\hline LOC_Os02g12130.1 & Cysteine-rich receptor-like protein kinase 35 precursor & 13.3946 & $1.8 \mathrm{E}+35$ \\
\hline LOC_Os01g41110.1 & Expressed protein & 1.98789 & $1.8 \mathrm{E}+35$ \\
\hline LOC_Os01g04560.1 & Expressed protein & 9.88668 & $1.8 \mathrm{E}+35$ \\
\hline LOC_Os11g40890.1 & Expressed protein & 211611 & $1.8 \mathrm{E}+35$ \\
\hline LOC_Os11g41100.1 & Expressed protein & 27938.4 & $1.8 \mathrm{E}+35$ \\
\hline $\mathrm{LOC}^{-} \mathrm{Os} 12 \mathrm{~g} 41570.1$ & Expressed protein & 3.59331 & $1.8 \mathrm{E}+35$ \\
\hline LOC_Os01g66760.1 & Inactive receptor kinase At2g26730 precursor & 0.788876 & $1.8 \mathrm{E}+35$ \\
\hline $\mathrm{LOC}^{-}$Os $06 \mathrm{~g} 10790.1$ & Lectin-like receptor kinase & 4.54422 & $1.8 \mathrm{E}+35$ \\
\hline LOC_Os07g04010.1 & Lectin-like receptor kinase & 1.48381 & $1.8 \mathrm{E}+35$ \\
\hline LOC_Os02g40130.1 & Leucine-rich & 1.09946 & $1.8 \mathrm{E}+35$ \\
\hline LOC_Os02g56370.1 & OsWAK20 - OsWAK receptor-like protein kinase & 0.909119 & $1.8 \mathrm{E}+35$ \\
\hline LOC_Os04g29580.1 & OsWAK37 - OsWAK short gene & 0.804394 & $1.8 \mathrm{E}+35$ \\
\hline LOC_Os04g29930.1 & OsWAK42 - OsWAK receptor-like protein kinase & 0.880981 & $1.8 \mathrm{E}+35$ \\
\hline LOC_Os04g29960.1 & OsWAK43 - OsWAK receptor-like protein kinase & 2.00163 & $1.8 \mathrm{E}+35$ \\
\hline LOC_Os04g30160.1 & OsWAK46 - OsWAK receptor-like protein kinase & 0.811559 & $1.8 \mathrm{E}+35$ \\
\hline LOC_Os07g31210.1 & OsWAK70 - OsWAK receptor-like cytoplasmic kinase & 4.04916 & $1.8 \mathrm{E}+35$ \\
\hline LOC_Os06g47650.1 & Phytosulfokine receptor precursor & 4.33848 & $1.8 \mathrm{E}+35$ \\
\hline LOC_Os01g02400.1 & Protein kinase domain containing protein & 15.7548 & $1.8 \mathrm{E}+35$ \\
\hline $\mathrm{LOC}^{-}$Os $01 \mathrm{~g} 02420.1$ & Protein kinase domain containing protein & 1.30291 & $1.8 \mathrm{E}+35$ \\
\hline LOC_Os11g44500.1 & Protein kinase domain containing protein & 96.4635 & $1.8 \mathrm{E}+35$ \\
\hline $\mathrm{LOC}^{-}$Os $11 \mathrm{~g} 46880.1$ & Protein kinase domain containing protein & 59.7802 & $1.8 \mathrm{E}+35$ \\
\hline LOC_Os04g01890.1 & Protein kinase & 1.29413 & $1.8 \mathrm{E}+35$ \\
\hline LOC_Os11g44430.1 & Protein kinase & 9.31762 & $1.8 \mathrm{E}+35$ \\
\hline LOC_Os11g47180.1 & Receptor-like protein kinase 2 precursor & 3.23605 & $1.8 \mathrm{E}+35$ \\
\hline LOC_Os02g13430.1 & Receptor-like protein kinase 5 precursor & 12280.7 & $1.8 \mathrm{E}+35$ \\
\hline LOC_Os11g47210.1 & Receptor-like protein kinase 5 precursor & 5.32406 & $1.8 \mathrm{E}+35$ \\
\hline LOC_Os11g12560.1 & Receptor-like protein kinase HAIKU2 precursor & 3.03439 & $1.8 \mathrm{E}+35$ \\
\hline LOC_Os01g02690.1 & Resistance-related receptor-like kinase & 1.39273 & $1.8 \mathrm{E}+35$ \\
\hline LOC_Os01g04570.2 & Ser/Thr protein kinase & 10.051 & $1.8 \mathrm{E}+35$ \\
\hline LOC_Os04g54120.1 & Serine/threonine-protein kinase receptor precursor & 9.45247 & $1.8 \mathrm{E}+35$ \\
\hline LOC_Os05g16430.1 & SHR5-receptor-like kinase & 0.922758 & $1.8 \mathrm{E}+35$ \\
\hline $\mathrm{LOC}^{-}$Os $08 \mathrm{~g} 13870.1$ & S-locus lectin protein kinase family protein & 14026.5 & $1.8 \mathrm{E}+35$ \\
\hline LOC_Os07g35004.1 & TKL_IRAK_DUF26-la.4 - DUF26 kinases & 1.73106 & $1.8 \mathrm{E}+35$ \\
\hline LOC_Os07g35390.1 & TKL_IRAK_DUF26-lc.17-DUF26 kinases & 1.63624 & $1.8 \mathrm{E}+35$ \\
\hline
\end{tabular}

Table 5. Genes validated by RT-qPCR in the Douradão and Primavera cultivars. The FPKM values are related to the drought treatment for Douradão (D 30) and Primavera (P 50). The Log2 values are related to the gene expression differences between the two cultivars.

\begin{tabular}{|c|c|c|c|c|}
\hline Gene Model & Protein name & FPKM (D 30) & FPKM (P 50) & $\log 2$ \\
\hline LOC_Os01g74470.1 & $\mathrm{ABC}$ transporter, ATP-binding protein & 8.73E-01 & 0 & $1.80 \mathrm{E}+35$ \\
\hline LOC_Os03g04060.1 & CHIT16-Chitinase family protein precursor & 399.033 & 75.1217 & 2.4092 \\
\hline LOC_Os06g51060.1 & CHIT8-Chitinase family protein precursor & 138.455 & 20.9345 & 2.72546 \\
\hline LOC_Os06g 13720.1 & Dehydrogenase E1 component domain & 4.99062 & 86.9669 & -4.12317 \\
\hline LOC_Os01g71350.1 & Glycosyl hydrolases family 17 & 61.8972 & 2.59894 & 4.57388 \\
\hline LOC_Os01g73200.1 & Peroxidase precursor & $2.75 \mathrm{E}+00$ & 0 & $1.80 \mathrm{E}+35$ \\
\hline LOC_Os12g02060.1 & Peroxidase precursor & $1.31 \mathrm{E}+00$ & 0 & $1.80 \mathrm{E}+35$ \\
\hline LOC_Os01g42380.1 & Pleiotropic drug resistance protein & $2.18 \mathrm{E}+00$ & 0 & $1.80 \mathrm{E}+35$ \\
\hline LOC_Os03g04970.1 & T-complex protein & $1.60 \mathrm{E}+00$ & 0 & $1.80 \mathrm{E}+35$ \\
\hline LOC_Os01g07530.1 & Uncharacterized glycosyltransferase & 12.2488 & 52.9269 & -2.11136 \\
\hline
\end{tabular}

\section{Transcription factor identification}

Twelve transcription factor (TF) families were identified from the $17 \mathrm{TF}$ differentially expressed genes between the drought and control treatments of Douradão, whereas 14 $\mathrm{TF}$ families were identified from $41 \mathrm{TF}$ differentially expressed genes in Primavera (Table 
6). The search for possible TFs among the differentially expressed genes across the two cultivars identified six genes belonging to four families of TFs, all of which were upregulated in Douradão compared to Primavera under water-deficient conditions. The TF families were bHLH (LOC_Os01g09930.1), MYB (LOC_Os07g48870.1 and LOC_Os08g15020.1), NAC (LOC_Os06g33940.1 and LOC_Os10g42130.1), and WRKY (LOC_Os08g29660.1).

Table 6. Number of overexpressed genes identified in each transcription factor family in Douradão and Primavera cultivars under drought.

\begin{tabular}{lcc}
\hline Transcription factor family & Douradão & Primavera \\
\hline AP2/EREBP, APETALA2/Ethylene-responsive element binding protein & 1 & 8 \\
Aux/IAA & 1 & 2 \\
bHLH, Basic Helix-Loop-Helix & 4 & 3 \\
bZIP & - & 2 \\
C2C2(Zn) CO-like, Constans-like zinc finger & 1 & - \\
C2C2(Zn) GATA & - & 1 \\
C2H2 zinc finger & 2 & 2 \\
Chromatin Remodeling Factors & 1 & 2 \\
G2-like, GARP & - & 1 \\
HB, Homeobox & 1 & 2 \\
HSF, Heat-shock & 1 & 4 \\
MYB domain & 1 & 4 \\
NAC domain & 1 & - \\
Putative & - & 2 \\
Unclassified & 2 & 4 \\
WRKY domain & 1 & 3 \\
Total & 17 & 40 \\
\hline
\end{tabular}

\section{Validation of the differentially expressed genes by RT-qPCR}

The 10 genes with higher expression in Douradão under drought treatment (Table 5) were selected to assess their expression using RT-qPCR. Seven out of these 10 genes were upregulated in the Douradão under drought treatment in comparison to the control treatment (Figure 7). The gene related to glycosyltransferase (LOC_Os01g07530.1) was upregulated in both Douradão and Primavera cultivars exposed to drought conditions in relation to their respective controls. The expression of another gene, glycosyl hydrolase family 17 (LOC_Os01g71350.1), increased 5.36-fold in Douradão under drought conditions, and was increased 3.54-fold in Primavera. The expression of a peroxidase precursor gene (LOC_ Os01g73200.1) increased 5.17-fold in Douradão under drought stress, and was downregulated (-0.08-fold) in Primavera. The gene of a T-complex protein (LOC_Os03g04970.1), annotated in the glyoxylate and dicarboxylate metabolism pathway, was upregulated (1.25fold) in Douradão and downregulated $(-0.29$-fold) in Primavera under drought stress. The gene encoding an ABC family protein (LOC_Os01g74470.1) showed an increase in expression during the drought treatment for Douradão (1.83-fold). Also in agreement with the RNA-seq, the gene CHIT8-Chitinase family protein precursor (LOC_Os06g51060.1) exhibited a 3.3-fold increase in expression in Douradão. The dehydrogenase E1 component domain containing protein (LOC_Os06g13720.1) was upregulated in Douradão (6.04-fold) and in Primavera (5.37-fold). The level of expression of the genes LOC_Os01g42380.1 (-2.32-fold) and LOC_Os03g04060.1 (-1.42-fold) and LOC_Os12g02060.1 (-0.82-fold) in Douradão were lower than in the control. 


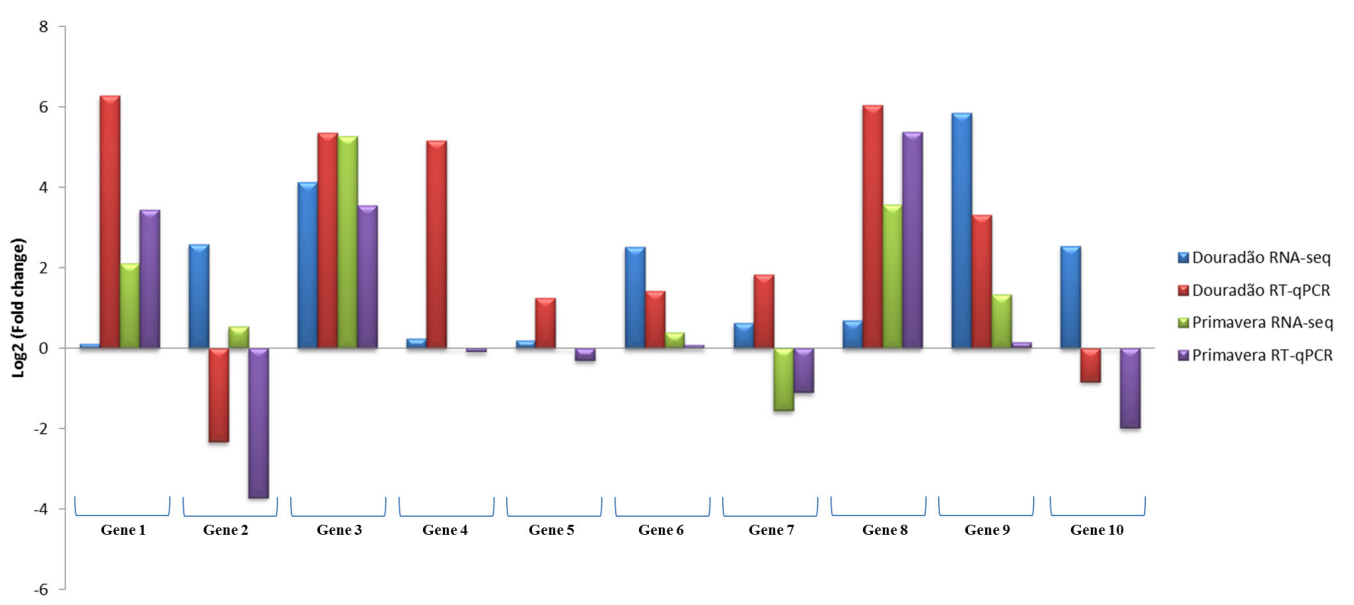

Figure 7. Expression levels of 10 genes determined by RT-qPCR. Douradão RNA-seq and RT-qPCR indicate the difference in gene expression identified between the drought treatment $(30 \%$ of $\mathrm{FC})$ and the control $(100 \%$ of FC) in the drought-tolerant cultivar; Primavera RNA-seq and RT-qPCR indicate the difference in gene expression identified by RNA-seq analysis between the drought treatment ( $30 \%$ of FC) and the control (100\% of FC) in the drought-sensitive cultivar. Gene $1=$ LOC Os01g07530.1, Gene $2=$ LOC Os01g42380.1, Gene $3=$ LOC Os01g71350.1, Gene 4 = LOC_Os01g73200.1, Gene 5 = LOC_Os01g74470.1, Gene 6 = LOC_Os03g04060.1, Gene 7 = LOC_Os03g04970.1, Gene 8 = LOC_Os06g13720.1, Gene 9 = LOC_Os06g51060.1, Gene $10=$ LOC_ Os12g02060.1.

\section{DISCUSSION}

The differential expression analysis of transcripts related to drought was estimated in two genotypes from Brazilian upland rice breeding programs. The transcripts found from this global expression analysis help to understand of the control mechanisms of rice drought tolerance, which is one of the starting points for development of upland rice cultivars more tolerant of this stress. Initially, a phenotyping protocol for the evaluation of drought-tolerant (Douradão) and drought-susceptible (Primavera) cultivars was established. At the end of the experiment, productivity was used as a criterion to evaluate drought tolerance during the reproductive stage, where drought appears more severe in rice fields. In rice breeding, selection for grain yield is an important parameter used to identify drought tolerant genotypes (Swamy and Kumar, 2013).

Gene expression analysis provides an overall picture of the changes that occur in the transcriptome of different parts of the plant under stress, furthering molecular characterization of the genes and pathways related to drought tolerance. Approximately $85 \%$ of the total number of sequenced reads was aligned with the publicly available rice reference genome $(O$. sativa ssp japonica, Nipponbare-MSU Rice Genome version 7.0), enabling the identification of differentially expressed transcripts between drought and control treatments and between Douradão and Primavera cultivars. The percentage of annotated reads was greater than those found by Gao et al. (2013), who observed that $72.3-75.6 \%$ of the reads originating from libraries of rice endosperms were perfectly aligned to sequences deposited in Gramene (http://www. gramene.org/). In addition, $87.2 \%$ of transcripts for Douradão were similar to the Nipponbare reference genome, while for Primavera the similarity was observed for $86.9 \%$ of transcripts. 
Although less differentially expressed genes were identified in Douradão in comparison to the susceptible Primavera cultivar, this set of genes were sufficient to enable yield to remain within acceptable levels under drought conditions, and this is an important characteristic that can be explored in rice breeding programs.

\section{Transcripts related to drought stress response in the tolerant cultivar}

The RNA-seq data identified genes exclusively expressed in the tolerant cultivar Douradão under drought (30\% of FC). Among these are the genes LOC_Os02g57720.1 and LOC_Os07g26630.1, which code for aquaporin proteins. These proteins are important waterspecific channels for ions or solutes, facilitating water flux along the existing osmotic gradient and increasing water retention in locations with a high density of osmotic agents. Plant aquaporins are divided into five subfamilies that comprise plasma membrane intrinsic protein (PIP), tonoplast intrinsic protein (TIP), nodulin 26-like intrinsic protein (NIP), small basic intrinsic protein (SIP), and uncategorized X intrinsic protein (XIP). Yooyongwech et al. (2013) related the increase in expression of proteins OsPIP1.2 and OsPIP2.1 with the stability of effective water usage in rice plants of the subspecies indica. Additionally, the genes LOC_

Os07g08160.1 and LOC_Os07g08150.1 showed high expression and encode the protein of the early light-induced protein (ELIP) type, associated with light-related stress. Members of this protein family accumulate within chloroplasts, more specifically in the thylakoid membranes, and are described as being involved in plant development under water-deficit conditions as well as in the photoprotection of leaves (Rizza et al., 2011). Another upregulated gene in Douradão under drought was LOC_Os03g01300.1, a LTPL40-Protease inhibitor/seed storage/LTP family protein precursor. Guo et al. (2013) showed that the overexpression of LTP3 in Arabidopsis leaves increased drought tolerance.

The cultivar Douradão also overexpressed the gene LOC_Os05g01140.1, which encodes a jasmonate $O$-methyltransferase. This enzyme is also called S-adenosyl-L-methionine: jasmonic acid carboxyl methyltransferase (JMT), and belongs to the family of transferases, which convert jasmonic acid (JA) to methyl jasmonate. Previous studies showed that both drought and high salinity increased JA levels in the leaves and roots of rice (Kiribuchi et al., 2005).

Two genes encoding the HSP20/alpha crystallin family protein (LOC_Os01g04350.1 and LOC_Os07g33350.2) were also identified among the most expressed genes in Douradão under drought treatment. The HSP20 proteins are ATP-independent molecular chaperones that usually form oligomeric protein complexes ranging from 9 to 50 subunits $(200-800 \mathrm{kDa})$ and act by avoiding protein denaturation, playing an important role in plant adaptation to various environmental stress conditions (Cashikar et al., 2005).

Douradão overexpressed genes under drought that are also associated with the functional subcategory protein kinase, the second largest among differentially expressed genes between Douradão and Primavera. Protein kinases regulate many cellular processes, including responses to environmental stimuli, such as water deficiency. Among the identified protein kinase genes, there were two Ser/Thr kinases (LOC_Os01g04570.2 and LOC_Os04g54120.1). In Arabidopsis, genes of the CIPK3 Ser/Thr protein kinase are associated with calcium sensing (calcineurin B-like), which regulates the response mediated by ABA during germination and induces the expression of genes during the stress responses (Kim et al., 2003). 


\section{Transcription factors}

In this study, genes of the ABA-dependent TF families' bHLH, MYB, NAC, and WRKY were identified. ABA-independent TFs, such as DREB1 and DREB2, were not identified because these are induced immediately after the occurrence of drought, cold or salt abiotic stresses (Kumar et al., 2013). Since the rice leaf tissues for RNA extraction were collected some days after the beginning of the drought stress, ABA-independent TFs would not be identified in this study. Basic helix-loop-helix (bHLH) proteins constitute one of the largest families of eukaryotic TFs and are involved in numerous regulatory processes, such as involvement in plant developmental processes, light perception, phosphate and iron homeostasis, and phytohormone synthesis pathways (Hiruma et al., 2011). Seo et al. (2011) demonstrated that the rice gene $O s b H L H 148$ is responsible for drought tolerance as a signaling component that is modulated by jasmonic acid.

The genes coding for MYB-type proteins (LOC_Os07g48870.1 and LOC_ Os08g15020.1) were upregulated in Douradão under drought treatment. The TFs MYC and MYB are proteins that are only synthesized after significant accumulation of endogenous ABA as a result of stress responses. The NAC TF family (LOC Os06g33940.1 and LOC Os10g42130.1) was upregulated in Douradão under drought treatment, and this family has been functionally associated with a wide variety of stresses, such as drought, high salinity, pathological bacterial agents, fungi, and senescence (Balazadeh et al., 2008). One gene of the TF family WRKY (LOC_Os08g29660.1) was also upregulated in Douradão under drought treatment. This TF family is known to play a crucial role in the regulation of many stress reactions in plants, such as protein WRKY40, which is modulated by the phytohormones ABA and jasmonic acid (Chen et al., 2010).

\section{RT-qPCR gene expression validation}

Seven of 10 genes analyzed by RT-qPCR were identified as overexpressed in Douradão under drought conditions in comparison to the control treatment, and confirmed the expected result obtained from RNA-seq. The gene LOC_Os06g51060.1 encodes the chitinase CHIT8. Chitinases catalyze the hydrolytic cleavage of the glycosidic $\beta-1,4$ bonds present in biopolymers of $\mathrm{N}$-acetylglycosamine, predominantly chitin, and have previously been related to drought response in strawberry (Raeini-Sarjaz and Chalavi, 2011). The gene LOC_Os01g71350.1 encodes a glycosyl hydrolase family 17 protein, and it was identified as homologous to the Arabidopsis gene AT3G57260.1 (beta-1,3-glucanase 2, a Pathogenesis-Related protein-PR). In Arabidopsis thaliana three proteins of this type (PR1, PR2, and PR5) were associated with an increase in drought tolerance, probably by regulating stomatal movements (Liu et al., 2013). Cal et al. (2013) identified several glycosyl hydrolases differentially expressed under drought, including two xyloglucan endotransglucosylase/hydrolases (XTHs). The gene LOC_Os01g73200.1, a peroxidase precursor, is an ortholog of AT1G71695.1 from A. thaliana, which is associated with the removal of $\mathrm{H}_{2} \mathrm{O}_{2}$, oxidation of toxic reductants, biosynthesis and degradation of lignin, suberization, auxin catabolism, and response to environmental stresses, such as wounding, pathogen attack, and oxidative stress (Ascencio-Ibáñez et al., 2008). This enzyme acts in the phenylpropanoid biosynthesis, pathway associated with drought tolerance mechanisms. The absence of this protein could reduce the level of flavonoids, secondary metabolites involved in the response to different types of 
stress, which are synthesized from phenylpropanoids (Rasmussen et al., 2012). The gene LOC_Os01g74470.1 encodes a protein of the ABC (ATP-binding cassette) family, which is related to membrane transport, and is involved in secreting pheromones, regulating mitochondrial function, vacuolar detoxification, drug resistance, and stress adaptation (Rea, 2007). Kang et al. (2010) showed evidence for ABC transporter-mediated phytohormone ABA uptake and its importance for rapid responses to environmental stress in A. thaliana. The gene LOC_Os01g07530.1, a glycosyltransferase, is an ortholog of the gene AT5G40390 from Arabidopsis. In the stachyose biosynthesis pathway, this protein is involved in the production of raffinose, a trisaccharide composed of galactose, fructose, and glucose. In rice, accumulation of raffinose is associated with heat shock and drought stress responses $(\mathrm{Wu}$ et al., 2009). The gene LOC_Os06g13720.1, which encodes the enzyme dehydrogenase E1, is homologous to the pyruvate dehydrogenase gene AT1G24180 from Arabidopsis. This enzyme acts in four different pathways (pyruvate metabolism, citrate cycle/TCA cycle, glycolysis/gluconeogenesis, and butanoate metabolism), and is responsible for the production of chemical energy (ATP) from the degradation of sugars. Two genes were identified in the Purine metabolism pathway, LOC_Os01g42380.1, which encodes a pleiotropic drugresistance protein (PDR) and LOC_Os03g04970.1, which encodes a T-complex protein. The gene LOC_Os01g42380.1 has an ortholog in A. thaliana, AT1G02520.1, which is part of the ABC family (TAIR, 2014). The gene LOC_Os03g04970.1-similar to Arabidopsis mitochondrial chaperonin 60 (AT3G23990.1), has an essential function in protein homeostasis under normal conditions and is highly responsive to various stresses (Demirevska et al., 2008).

This study identified a series of transcripts in tropical rice varieties previously related to drought tolerance in temperate rice varieties. As drought is a complex trait, the identified transcripts individually show limited effects in phenotype, and for this reason, must be analyzed as a group of useful genes, with the contributions of the interacting alleles from these loci. With this approach, it will be possible to identify, for example, Cis-acting elements, in order to better explain the variation in expression observed at the protein or metabolite levels after the occurrence of drought in rice, accumulating experimentally supported knowledge to be applied in important pathways related to this stress. These transcripts will also be used to search for allelic variants of these genes through analysis of polymorphic SNPs in GenBank accessions of upland rice, aiming to develop cultivars with the best combination of these alleles, which will result in materials with high yield potential upon the occurrence of drought during the reproductive phase. Most of the genes identified in the tolerant cultivar Douradão in response to drought stress act in detoxification, water transportation, and metabolism maintenance during the stress. In addition, genes from photosynthesis and sugar degradation pathways were also found in both tolerant and susceptible cultivars. The identification of transcripts belonging to different metabolic pathways associated with responses to water deficit strengthens the idea of great complexity of the genetic control of drought tolerance, and provides candidates for marker assisted selection of upland rice breeding populations or to be overexpressed in genetically modified rice as strategies to develop cultivars with superior performance to drought tolerance.

\section{ACKNOWLEDGMENTS}

The authors thank Embrapa for financial support and the Conselho Nacional de Desenvolvimento Científico e Tecnológico (CNPq) for the grants awarded to C. Brondani, R.D.D. 
Silveira, and R.P. Vianello.

\section{$\underline{\text { Supplementary material }}$}

\section{REFERENCES}

Altschul SF, Madden TL, Schaffer AA, Zhang J, et al. (1997). Gapped BLAST and PSI-BLAST: A new generation of protein database search programs. Nucl. Acids Res. 25: 3389-3402.

Ascencio-Ibáñez JT, Sozzani R, Lee TJ, Chu TM, et al. (2008). Global analysis of Arabidopsis gene expression uncovers a complex array of changes impacting pathogen response and cell cycle during geminivirus infection. Plant Physiol. 148: 436-454.

Balazadeh S, Parlitz S, Mueller-Roeber B and Meyer RC (2008). Natural developmental variations in leaf and plant senescence in Arabidopsis thaliana. Plant Biol. 10: 136-147.

Boudsocq M and Laurière C (2005). Osmotic signaling in plants. Multiple pathways mediated by emerging kinase families. Plant Physiol. 138: 1185-94.

Cal AJ, Liu D, Mauleon R, Hsing Y-IC, et al. (2013). Transcriptome profiling of leaf elongation zone under drought in contrasting rice cultivars. PLoS One 8: e54537.

Cashikar AG, Duennwald M and Lindquist SL (2005). A chaperone pathway in protein disaggregation: Hsp26 alters the nature of protein aggregates to facilitate reactivation by Hsp104. J. Biol. Chem. 280: 23869-23875.

Cattivelli L, Rizza F, Badeck FW, Mazzucotelli E, et al. (2008). Drought tolerance improvement in crop plants: An integrated view from breeding to genomics. Field Crop. Res. 105: 1-14.

Chen H, Lai Z, Shi J, Xiao Y, et al. (2010). Roles of Arabidopsis WRKY18, WRKY40 and WRKY60 transcription factors in plant responses to abscisic acid and abiotic stress. BMC Plant Biol. 10: 281.

Civelek M and Lusis AJ (2014). Systems genetics approaches to understand complex traits. Nature Rev. Genet. 15: 34-48.

Collins NC, Tardieu F and Tuberosa R (2008). Quantitative trait loci and crop performance under abiotic stress: where do we stand? Plant Physiol. 147: 469-486.

Conesa A, Gotz S, Gracía-Gomez JM, Terol J, et al. (2005). Blast2GO: a universal tool for annotation, visualization and analysis in functional genomics research. Bioinformatics 21: 3674-3676.

Counce PA, Keisling TC and Mitchell AJ (2000). A uniform, objective, and adaptive system for expressing rice development. Crop Sci. 40: 436-443.

Demirevska K, Simova-Stoilova L, Vassileva V and Feller U (2008). Rubisco and some chaperone protein responses to water stress and rewatering at early seedling growth of drought sensitive and tolerant wheat varieties. Plant Growth Regul. 56: 97-106.

Ding X, Li X and Xiong L (2013). Insight into differential responses of upland and paddy rice to drought stress by comparative expression profiling analysis. Int. J. Mol. Sci. 14: 5214-5238.

Gao Y, Xu H, Shen Y and Wang J (2013). Transcriptomic analysis of rice (Oryza sativa) endosperm using the RNA-Seq technique. Plant Mol. Biol. 81: 363-378.

Godfray HC, Beddington JR, Crute IR, Haddad L, et al. (2010). Food security: the challenge of feeding 9 billion people. Science 327: 812-818.

Guo L, Yang H, Zhang X and Yang S (2013). Lipid transfer protein 3 as a target of MYB96 mediates freezing and drought stress in Arabidopsis. J. Exp. Bot. 64: 1755-1767.

Hiruma K, Nishiuchi T, Kato T, Bednarek P, et al. (2011). Arabidopsis ENHANCED DISEASE RESISTANCE 1 is required for pathogen-induced expression of plant defensins in nonhost resistance, and acts through interference of MYC2-mediated repressor function. Plant J. 67: 980-992.

Kang J, Hwang JU, Lee M, Kim YY, et al. (2010). PDR-type ABC transporter mediates cellular uptake of the phytohormone abscisic acid. Proc. Natl. Acad. Sci. U. S. A. 107: 2355-2360.

Kim CY, Liu Y, Thorne ET, Yang H, et al. (2003). Activation of a stress-responsive mitogen-activated protein kinase cascade induces the biosynthesis of ethylene in plants. Plant Cell 15: 2707-2718.

Kiribuchi K, Jikumaru Y, Kaku H, Minami E, et al. (2005). Involvement of the basic helix-loop-helix transcription factor RERJ1 in wounding and drought stress responses in rice plants. Biosci. Biotechnol. Biochem. 69: 1042-1044.

Kumar K, Kumar M, Kim SR, Ryu H, et al. (2013). Insights into genomics of salt stress response in rice. Rice 6: 27.

Liu WX, Zhang FC, Zhang WZ, Song LF, et al. (2013). Arabidopsis Di19 functions as a transcription factor and modulates PR1, PR2, and PR5 expression in response to drought stress. Mol. Plant 6: 1487-1502.

Livak KJ, Schmittgen TD (2001) Analysis of relative gene expression data using realtime quantitative PCR and the 
$2^{\Delta \Lambda} \mathrm{C}(\mathrm{T})$ Method. Methods 25: 402-408.

Moumeni A, Satoh K, Kondoh H, Asano T, et al. (2011). Comparative analysis of root transcriptome profiles of two pairs of drought-tolerant and susceptible rice near-isogenic lines under different drought stress. BMC Plant Biol. 11: 174.

Nagalakshmi U, Wang Z, Waern K, Shou C, et al. (2008). The transcriptional landscape of the yeast genome defined by RNA sequencing. Science 320: 1344-1349.

Rabbani MA, Maruyama K, Abe H, Khan MA, et al. (2003). Monitoring expression profiles of rice genes under cold, drought, and high-salinity stresses and abscisic acid application using cDNA microarray and RNA get-blot analyses. Plant Physiol. 133: 1755-1767.

Raeini-Sarjaz M and Chalavi V (2011). Effects of water stress and constitutive expression of a drought induced chitinase gene on water-use efficiency and carbon isotope composition of strawberry. J. Appl. Bot. Food Qual. 84: 90-94.

Rasmussen S, Parsons AJ and Jones CS (2012). Metabolomics of forage plants: a review. Ann. Bot. 110: 1281-1290.

R Development Core Team (2008). R: A language and environment for statistical computing. R Foundation for Statistical Computing, Vienna, Austria. Available at [http://www.R-project.org].

Rea PA (2007). Plant ATP-binding cassette transporters. Annu. Rev. Plant Biol. 58: 347-375.

Recchia GH, Caldas DGG, Beraldo ALA, da Silva MJ, et al. (2013). Transcriptional analysis of drought-induced genes in the roots of a tolerant genotype of the common bean (Phaseolus vulgaris L.). Int. J. Mol. Sci. 14: 7155-7179.

Rizza A, Boccaccini A, Lopez-Vidriero I, Costantino P, et al. (2011). Inactivation of the ELIP1 and ELIP2 genes affects Arabidopsis seed germination. New Phytol. 190: 896-905.

Santos AB and Rabelo RR (2008). Informações técnicas para a cultura do arroz irrigado no estado do tocantins. Embrapa Arroz e Feijão, Santo Antônio de Goiás.

Seo JS, Joo J, Kim MJ, Kim YK, et al. (2011). OsbHLH148, a basic helix-loop-helix protein, interacts with OsJAZ proteins in a jasmonate signaling pathway leading to drought tolerance in rice. Plant J. 65: 907-921.

Swamy BPM and Kumar A (2013). Genomics-based precision breeding approaches to improve drought tolerance in rice. Biotechnol. Adv. 31: 1308-1318.

TAIR. The Arabidopsis Information Resource. Available at [http://www.arabidopsis.org/servlets/TairObject?name=AT1 G02520.1\&type=gene]. Accessed June 3, 2014.

Trapnell C, Hendrickson DG, Sauvageau M, Goff F, et al. (2013). Differential analysis of gene regulation at transcript resolution with RNA-Seq. Nat. Biotechnol. 31: 46-53.

Wang D, Pan Y, Zhao X, Zhu L, et al (2011). Genome-wide temporal-spatial gene expression profiling of drought responsiveness in rice. BMC Genomics 12: 149.

Wu X, Kishitani S, Ito Y and Toriyama K (2009). Accumulation of raffinose in rice seedlings overexpressing OsWRKY11 in relation to desiccation tolerance. Plant Biotechnol. 26: 431-434.

Yooyongwech S, Cha-um S and Supaibulwatana K (2013). Water relation and aquaporin genes (PIP1;2 and PIP2;1) expression at the reproductive stage of rice (Oryza sativa L. spp. indica) mutant subjected to water deficit stress. Plant Omics 6: 79-85. 